\title{
Clinical Significance and Phenotype of MTA1 Expression in Esophageal Squamous Cell Carcinoma
}

\author{
HIROAKI HONJO ${ }^{1}$, YASUSHI TOH ${ }^{2}$, MAKOTO SOHDA ${ }^{1}$, SHIGEMASA SUZUKI ${ }^{1}$, \\ KYOICHI KAIRA ${ }^{3}$, YOSHIKATSU KANAI ${ }^{4}$, SHUSHI NAGAMORI ${ }^{4}$, TETSUNARI OYAMA ${ }^{5}$, \\ TAKEHIKO YOKOBORI ${ }^{1}$, TATSUYA MIYAZAKI ${ }^{1}$ and HIROYUKI KUWANO ${ }^{1}$ \\ ${ }^{1}$ Department of General Surgical Science, Gunma University, Graduate School of Medicine, Gunma, Japan; \\ ${ }^{2}$ Department of Gastroenterological Surgery, National Kyushu Cancer Center, Fukuoka, Japan; \\ ${ }^{3}$ Department of Oncology Clinical Development, Graduate School of Medicine, Gunma University, Gunma, Japan; \\ ${ }^{4}$ Department of Bio-system Pharmacology, Graduate School of Medicine, Osaka University, Osaka, Japan; \\ ${ }^{5}$ Department of Diagnostic Pathology, Graduate School of Medicine, Gunma University, Gunma, Japan
}

\begin{abstract}
Background/Aim: Metastasis-associated gene 1 (MTA1) is considered a potential prognostic factor in esophageal cancer. We investigated the clinical relationship between MTA1, LAT1, and tumor metabolism, as evaluated by positron emission tomography (PET) in esophageal squamous cell carcinoma. Materials and Methods: We analyzed 142 esophageal squamous cell carcinoma patients who underwent curative resection without preoperative treatment. MTA1 expression was assessed by immuno-zahistochemistry, and tested against standardized uptake values from preoperative PET-CT. The association among MTA1, LAT1, and ${ }^{18}$ FAMT PET results were analyzed. Results: MTAl staining was observed in 82 of 142 cancer tissues. Five-year overall survival was $69.9 \%$ in the absence of MTA1, but $50.7 \%$ otherwise $(p=0.021)$, while disease-free survival was $66.5 \%$ and $49.0 \%$ ( $p=0.071)$, respectively. Abnormal ${ }^{18}$ FAMT accumulation was noted in 13 patients without MTAl and in 18 patients with MTA1 ( $p=0.079)$, with maximum standardized uptake value $1.6 \pm 1.6$ and $2.7 \pm 1.6$, respectively $(p=0.036)$. MTA1 expression was positively correlated with LAT1 $(p=0.013)$ and CD34 $(p=0.034)$ expression, but not with Ki-67 ( $p=0.078)$. Conclusion: MTAl shows promise as a diagnostic and prognostic marker in esophageal cancer, and we anticipate that the gene will also prove to be a good therapeutic target.
\end{abstract}

This article is freely accessible online.

Correspondence to: Hiroaki Honjo, MD, Department of General Surgical Science, Gunma University, Graduate School of Medicine, Showa-machi, Maebashi, Gunma 371-8511, Japan. Tel: +81 272208224, Fax: +81 272208230, e-mail: honjoh@outlook.jp

Key Words: Esophageal cancer, squamous cell carcinoma, MTA1, FAMT-PET.
Esophageal cancer is the eighth most common cancer worldwide, and prognosis remains poor despite progress in combined-modality therapy (1). Esophageal cancer develops as two major histological forms, namely squamous cell carcinoma and adenocarcinoma. The former is common in Eastern Europe and Asia, especially Japan, while the latter is prevalent in western countries. Most patients are diagnosed at advanced stages, and thus follow an unfavorable clinical course. To improve prognosis, new biomarkers and therapeutic methods are needed.

Metastasis-associated gene 1 (MTA1), the first MTA gene to be identified, was originally found by Toh et al. (2) through differential screening of a cDNA library from rat metastatic breast tumors. MTA1 was also found to physically interact with histone deacetylase 1 (HDAC1) (3), remodel chromatin, and deacetylate histones via nucleosome remodeling histone deacetylation complexes (4). Subsequently, MTA1 was found to be widely up-regulated in human tumors (5). In addition, Toh et al. (6) recently reported that MTA1 overexpression is correlated with aggressive invasion, more extensive metastasis into lymph nodes, and worse pathologies. Thus, MTA1 may be a potential prognostic factor in esophageal squamous cell carcinoma (ESCC), although it is unclear how MTA1induced features can be clinically detected by imaging or other modalities.

In comparison to normal cells, tumor cells have increased demand for nutrients such as glucose and amino acids. Accordingly, imaging modalities that capture the enhanced metabolism in tumors, including positron emission tomography (PET), have been developed and exploited in cancer treatment (7). For example, PET with 2-[ $\left.{ }^{18} \mathrm{~F}\right]$-fluoro2-deoxy-D-glucose $\left({ }^{18} \mathrm{~F}\right.$-FDG $)$, which is taken up by tumor cells through glucose transporter 1 , has been widely used to diagnose malignant lesions (8). Indeed, this modality is 
useful not only to visualize tumor boundaries, but also to predict patient survival after esophageal cancer resection (9). Similarly, L- $\left[3-{ }^{18} \mathrm{~F}\right]$-a-methyltyrosine $\left({ }^{18} \mathrm{~F}\right.$-FAMT $)$ is used as an amino acid tracer to image various neoplasms by PET (10). Of note, ${ }^{18}$ F-FAMT is specifically taken up by neoplasms via L-type amino acid transporter 1 (LAT1), while ${ }^{18} \mathrm{~F}-\mathrm{FDG}$ is also taken up by non-tumor cells with ongoing inflammation or granulation, which may thereby generate false positives $(11,12)$. Previously, we demonstrated the value of ${ }^{18}$ F-FAMT imaging in treating esophageal cancer, and investigated the clinicopathological significance of LAT1 in $\operatorname{ESCC}(13,14)$. However, the clinical relationship between MTA1, LAT1, and tumor metabolism, as evaluated by PET (15), has not yet been investigated in ESCC.

\section{Materials and Methods}

Patients. We analyzed 142 patients who were diagnosed with ESCC by pathology, and who underwent curative resection without preoperative treatment at Gunma University Hospital between January 2000 and December 2007. Surgical procedures were considered curative when there was no evidence of residual tumor and resected margins were microscopically free of tumors. The cohort consisted of 126 males and 16 females between 41 and 83 years (mean 64.5 years). Five-year overall and disease-free survival were $65.0 \%$ and $56.5 \%$, respectively, with day of surgery considered as day 0 . Patient characteristics are listed in Table I. Tumor specimens were histologically classified according to World Health Organization criteria (16), and pathology was assessed according to TNM Classification of Malignant Tumors 7th edition by Union for International Cancer Control (17). Postoperative clinical course was evaluated based on outpatient medical records. Tumor recurrence was confirmed by standard gastrointestinal endoscopy and/or computed tomography (CT) or ${ }^{18} \mathrm{~F}-\mathrm{FDG}$ PET. Written informed consent was obtained from all patients with approval from the ethics committee at Gunma University Hospital.

MTA1 expression was assessed by immunohistochemistry, and tested against standardized uptake values from preoperative ${ }^{18} \mathrm{~F}$ FDG and ${ }^{18}$ FAMT PET. In addition, we examined the association between standardized uptake values and LAT1 expression, which was previously measured by immunohistochemistry in 42 of the 142 patients who underwent preoperative ${ }^{18}$ FAMT PET (15). Finally, we analyzed the association among MTA1, LAT1, and ${ }^{18}$ FAMT PET results using updated follow up data for these 42 patients.

Immunohistochemistry. MTA1: MTA1 expression was examined by immunohistochemistry of 4- $\mu \mathrm{m}$ paraffin sections of cancerous and normal esophageal epithelium, using a 1:300 dilution of the rabbit monoclonal antibody D40D1 (Cell Signaling Technology, Japan). Briefly, sections were deparaffinized, rehydrated, soaked in methanol with $0.3 \%$ hydrogen peroxide to quench endogenous peroxidase activity, and boiled in Immunosaver (Nishin EM, Tokyo, Japan) at $98^{\circ} \mathrm{C}$ for $45 \mathrm{~min}$ to maximize antigen exposure. Specimens were then blocked at room temperature for $30 \mathrm{~min}$ with Protein Block (Dako, CA, USA), probed with anti-MTA 1 overnight at $4^{\circ} \mathrm{C}$, and visualized with HISTOFINE Simple Stain MAX-PO (MULTI) (Nichirei, Tokyo, Japan) according to the manufacturer's protocol, using as chromogen $0.02 \%$ 3,3'-diaminobenzidine tetrahydrochloride in 50
$\mathrm{mM}$ ammonium acetate-citrate acid buffer supplemented with $0.005 \%$ hydrogen peroxide. Sections were counterstained with Mayer's hematoxylin, and mounted. Specimens not probed with primary antibody were used as negative control, and tumor tissues were considered to express MTA1 when stronger nuclear staining was observed in comparison to normal epithelial cells.

LAT1, Ki-67, and CD34. LAT1, Ki-67, and CD34 expression was previously measured by immunohistochemistry (18) using mouse monoclonal antibodies against LAT1 (provided by Dr. H Endou at J-Pharma, Tokyo, Japan and described in ref. 19, 1:3,200), CD34 (Nichirei, Tokyo, Japan, 1:800), and Ki-67 (Dako, Glostrup, Denmark, 1:40). Tissues were considered to express LAT1 when clear membrane staining was present regardless of cytoplasmic staining. In addition, LAT1 expression was deemed high when over $50 \%$ of cells in a tissue were stained. On the other hand, areas with a concentration of Ki-67 staining were considered hot spots, and at most four of such hot spots were evaluated in each specimen. At least $\sim 100$ nuclei in each hot spot were assessed, and cells with nuclear staining of any intensity were considered to express Ki-67. Finally, proliferative activity (Ki-67 index) was assessed as the percentage of stained nuclei. CD34-positive vessels in hot spots were also counted at $400 \times\left(0.26 \mathrm{~mm}^{2}\right.$ field area), and microvessel density was calculated as the number of microvessels per $0.26 \mathrm{~mm}^{2}$ field.

Sections were assessed by light microscopy by at least two of the authors blinded to both the sample and the patient outcome. Similarly, two authors independently graded staining intensity in all cases. To test intraobserver variability, each section was reassessed by the same investigators at least 4 weeks after the first assessment. Interobserver variability was also determined by comparing the initial measurements from two investigators.

${ }^{18} \mathrm{~F}$-FDG and ${ }^{18} \mathrm{~F}$-FAMT PET. Of the 142 patients, 117 underwent preoperative ${ }^{18} \mathrm{~F}$-FDG $\mathrm{PET}$, and another 42 underwent preoperative ${ }^{18}$ F-FAMT PET. Maximum standardized uptake values were evaluated, and set to zero if tracers did not clearly accumulate in the tumor. However, mean values were calculated based on all tissues regardless of accumulation.

Statistical analysis. Data were analyzed in StatMate ver 5.01. $\chi^{2}$ test and Fisher's exact test were used to examine relationships among categorical variables. Data from immunohistochemistry were averaged, and correlation among MTA1, LAT1, Ki-67, CD34, and standardized uptake values for ${ }^{18} \mathrm{~F}-\mathrm{FDG}$ and ${ }^{18} \mathrm{~F}$-FAMT were analyzed by nonparametric Spearman's rank test, with $p$-values less than 0.05 considered statistically significant. Survival rates were calculated by the Kaplan-Meier method, and statistical significance was determined by log-rank test. Cox proportional hazards model was used for univariate and multivariate analyses.

\section{Results}

MTA1 expression in cancer patients. Immunohistochemistry revealed diffuse MTA1 staining in 82 of 142 cancer tissues. MTA1 was detected exclusively in cancer nuclei, especially in cells that would otherwise have been normal epithelia, although expression was not observed in the basal layer (Figure 1). As can be seen in Table II, cancers expressing 
Table I. Patient characteristics.

\begin{tabular}{lc}
\hline Parameter & Number \\
\hline Gender & \\
Female & 16 \\
Male & 126 \\
Age & $64.5(41-83)^{*}$ \\
Pathological status (UICC 7th edition) & \\
Histology & \\
Well & 28 \\
Mod & 78 \\
Poor & 36 \\
Tumor depth & \\
pT1 & 63 \\
pT2 & 15 \\
pT3 & 58 \\
pT4 & 6 \\
Lymph node metastasis & \\
Absent & 59 \\
Present & 83 \\
Lymphatic permeation & \\
Absent & 28 \\
Present & 114 \\
Venous invasion & \\
Absent & Total n=142 \\
Present & \\
Recurrence & 37 \\
Absent & 105 \\
Present & \\
& \\
\hline
\end{tabular}

*Median (range). Well, Well differentiated; Mod, moderately differentiated; Poor, poorly differentiated.

MTA1 showed more progressed state. Five-year overall survival was $69.9 \%$ in the absence of MTA1, but $50.7 \%$ otherwise $(p=0.021)$, while disease-free survival was $66.5 \%$ and $49.0 \%(p=0.071)$, respectively (Figure 2$)$.

Lymph node metastasis was the only independent prognostic factor in multivariate analysis of both overall survival, with $\mathrm{HR}=2.03,95 \% \mathrm{CI}=1.06-3.90$, and $p=0.034$, and disease-free survival, with $\mathrm{HR}=2.23,95 \% \mathrm{CI}=1.13-4.48$, and $p 0.02$ (Table III).

Accumulation of ${ }^{18} \mathrm{~F}-\mathrm{FDG}$ and ${ }^{18} \mathrm{~F}$-FAMT in cancer tissues. Of 117 patients who underwent ${ }^{18}$ F-FDG PET, 68 expressed MTA1, and 49 did not. Abnormal ${ }^{18}$ F-FDG accumulation was observed in 62 patients who expressed MTA1, and in 36 patients who did not $(p=0.0104)$, with maximum standardized uptake value $7.3 \pm 5.8$ in the former and $6.7 \pm 4.3$ in the latter $(p=0.574)$.

On the other hand, MTA1 expression was observed in 21 of 42 patients who underwent preoperative ${ }^{18} \mathrm{~F}$-FAMT PET, but not in the other 21 patients. Abnormal ${ }^{18}$ FAMT accumulation
Table II. Tissues expressing metastasis-associated gene 1 (MTA1) were less differentiated $(p=0.015)$, and presented increased tumor depth $(p<0.01)$, lymphatic permeation $(p<0.01)$, vascular invasion $(p<0.01)$, and recurrence $(p=0.078)$.

\begin{tabular}{|c|c|c|c|}
\hline & $\begin{array}{l}\text { MTA1 negative } \\
\quad(\mathrm{n}=60)\end{array}$ & $\begin{array}{l}\text { MTA1 positive } \\
\quad(\mathrm{n}=82)\end{array}$ & $p$-Value \\
\hline \multicolumn{4}{|l|}{ Gender } \\
\hline Female & 9 & 7 & \multirow[t]{2}{*}{0.229} \\
\hline Male & 51 & 75 & \\
\hline $\operatorname{Age}^{1}$ & $63.7 \pm 7.7$ & $64.6 \pm 8.5$ & 0.528 \\
\hline \multicolumn{4}{|l|}{ Histology 2} \\
\hline Well-mod & 51 & 55 & \multirow[t]{2}{*}{0.015} \\
\hline Poor & 9 & 27 & \\
\hline \multicolumn{4}{|l|}{ Tumor depth ${ }^{2}$} \\
\hline pT1 & 35 & & \\
\hline pT2-4 & 25 & 54 & 0.0042 \\
\hline \multicolumn{4}{|c|}{ Lymph node metastasis ${ }^{2}$} \\
\hline Absent & 28 & 31 & \multirow[t]{2}{*}{0.290} \\
\hline Present & 32 & 51 & \\
\hline \multicolumn{4}{|c|}{ Lymphatic permeation $^{2}$} \\
\hline Absent & 19 & 9 & \multirow[t]{2}{*}{0.0022} \\
\hline Present & 41 & 73 & \\
\hline \multicolumn{4}{|c|}{ Venous invasion ${ }^{2}$} \\
\hline Absent & 24 & 13 & \multirow[t]{2}{*}{0.0012} \\
\hline Present & 36 & 69 & \\
\hline \multicolumn{4}{|l|}{ Recurrence $^{2}$} \\
\hline Absent & 41 & 44 & \multirow[t]{2}{*}{0.078} \\
\hline Present & 19 & 38 & \\
\hline
\end{tabular}

${ }^{1}$ mean \pm SD; ${ }^{2}$ UICC 7 th edition. Well, Well differentiated; Mod, moderately differentiated; Poor, poorly differentiated.

was noted in 13 patients without MTA1 and in 18 patients with MTA1 $(p=0.079)$, with maximum standardized uptake value $1.6 \pm 1.6$ and $2.7 \pm 1.6$, respectively $(p=0.036)$.

Expression of LAT1, Ki-67, CD34 in cancer patients. Analysis of LAT1, Ki-67, and CD34 expression in the same 42 patients who underwent preoperative ${ }^{18}$ F-FAMT PET indicated that LAT1 was weakly expressed in 16 of 21 patients without MTA1, but strongly expressed in the other 5 . In contrast, LAT1 was abundantly expressed in 13 of 21 patients with MTA1, but only weakly expressed in the other $8(p=.013)$. The Ki-67 index in patients without MTA1 was $39.6 \pm 20.0$, but $50.2 \pm 18.0$ in all others $(p=0.078)$, with microvessel density $16.4 \pm 6.2$ in the former and $21.1 \pm 7.7(p=0.034)$ in the latter.

\section{Discussion}

We examined the clinicopathological significance of MTA1 in ESCC patients who underwent radical surgery without preoperative treatment, using new and published (but 
A

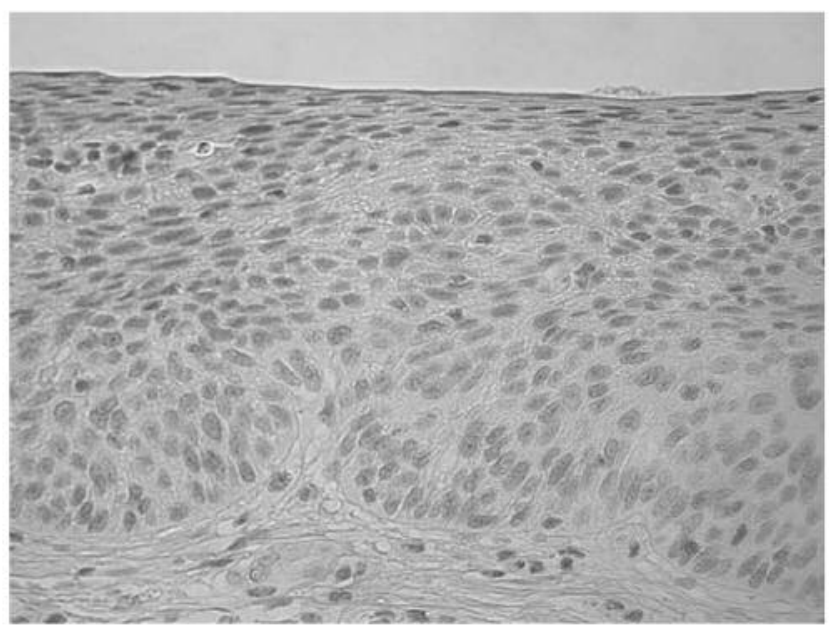

B

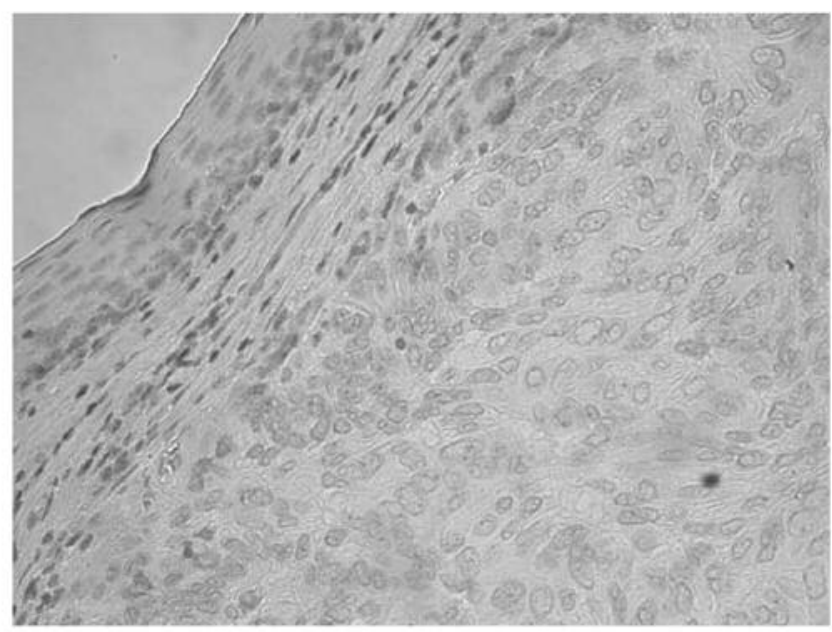

C
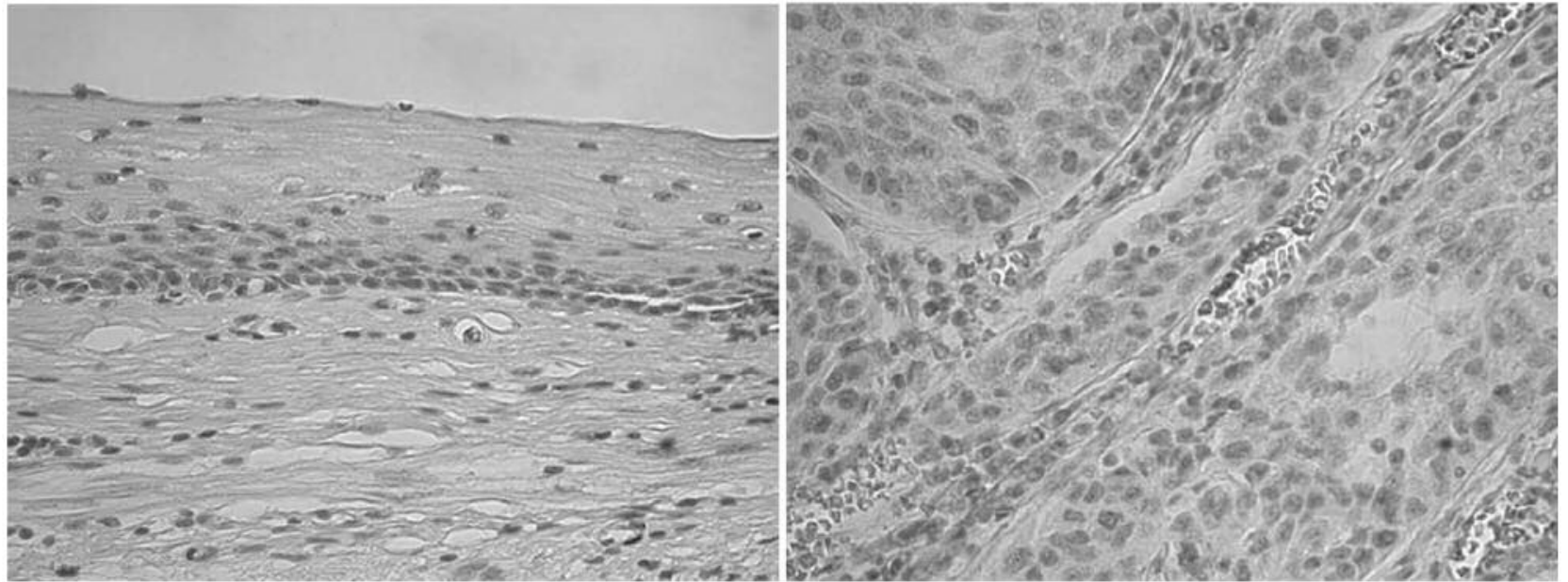

D
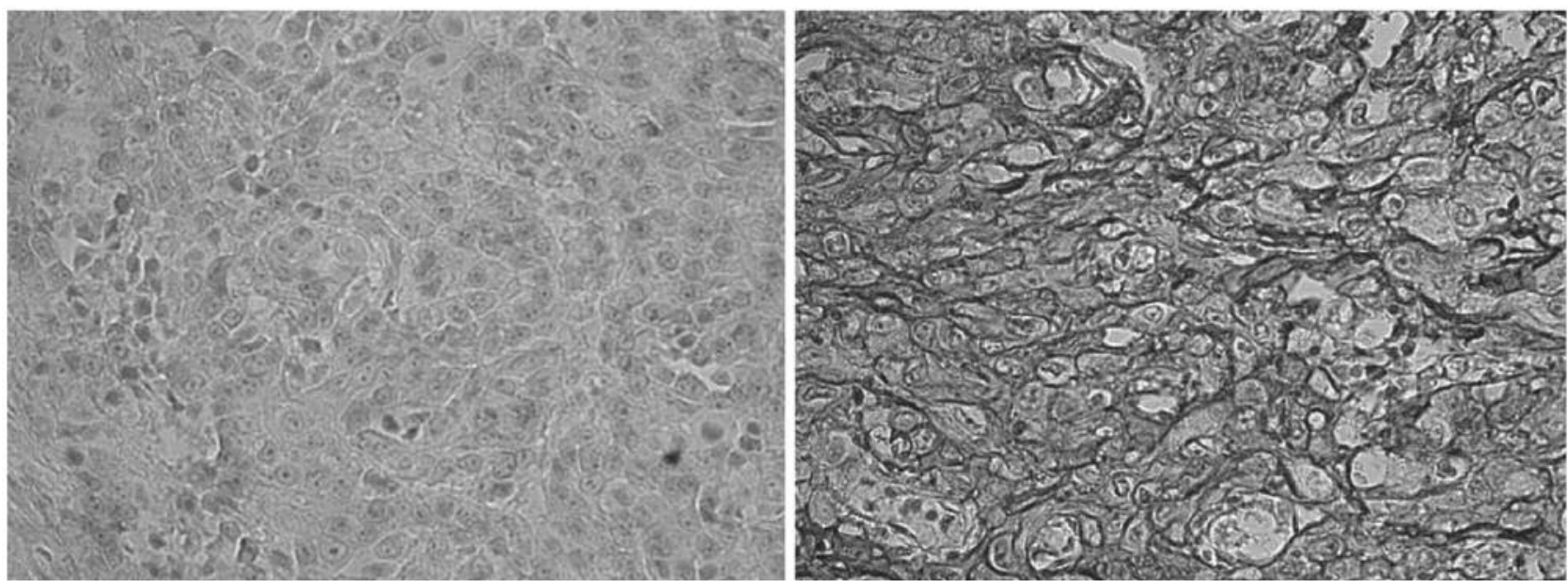

Figure 1. Continued 
E
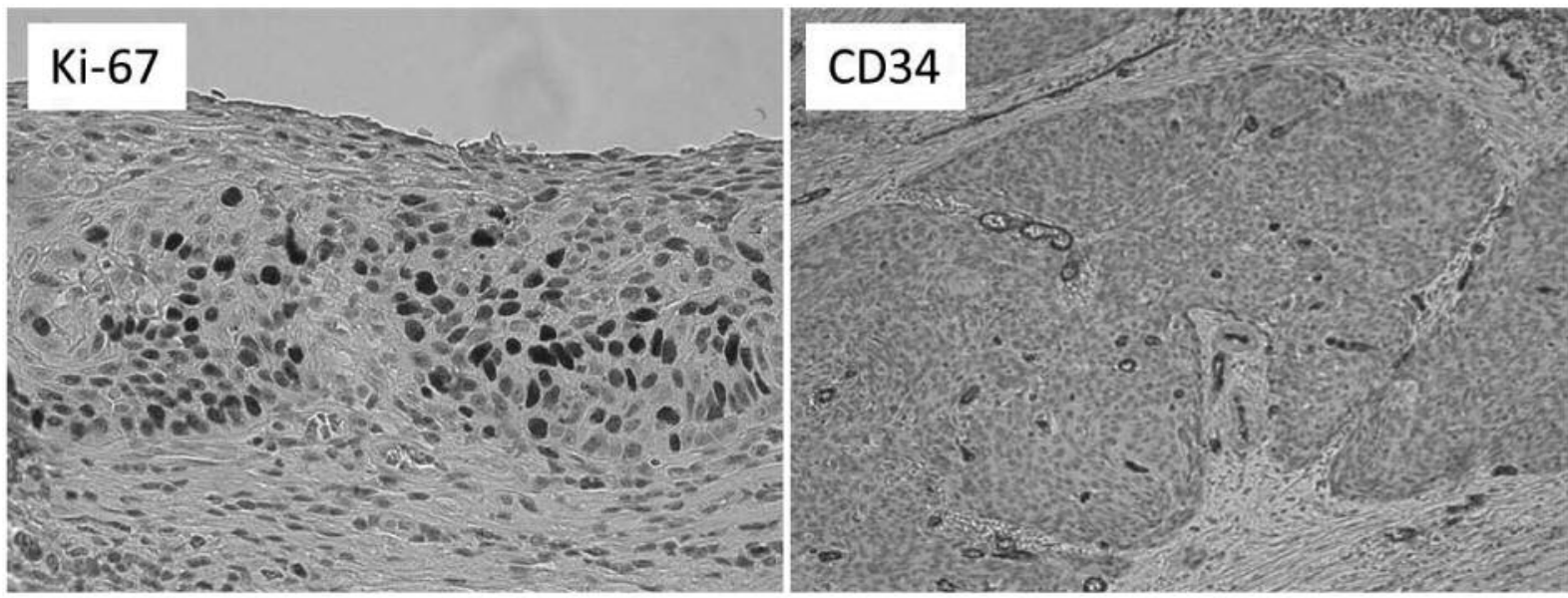

Figure 1. (A-C) Immunostaining indicates accumulation of metastasis-associated gene 1 (MTA1) in nuclei. Tumors were considered to express MTA1 when stronger nuclear staining was observed in comparison to normal epithelial cells (A). Otherwise, tissues were considered to not express MTA1 $(B, C)$. (D) Immunostaining indicates expression of L-type amino-acid transporter 1 (LAT1) in cell membranes (right). The panel on the left is a tissue not expressing LAT1. Tumors in which over $50 \%$ of cells were stained were considered to strongly express LAT1. (E) Immunostaining for Ki-67 and CD34. Ki-67 index was calculated as the ratio of Ki-67-stained cells to all cells. Microvessel index was calculated as the number of CD34-stained cells per field at 400x.

A

\section{Overall survival}

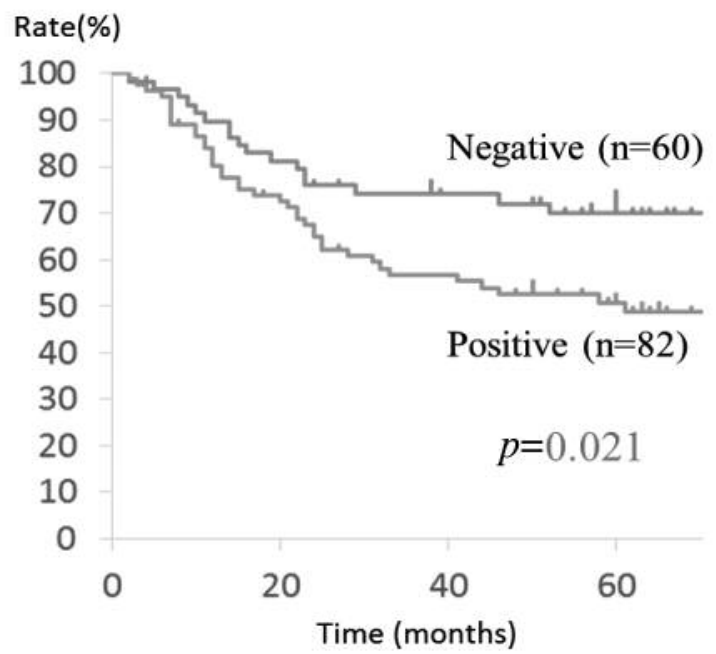

$\mathrm{B}$

\section{Disease free survival}

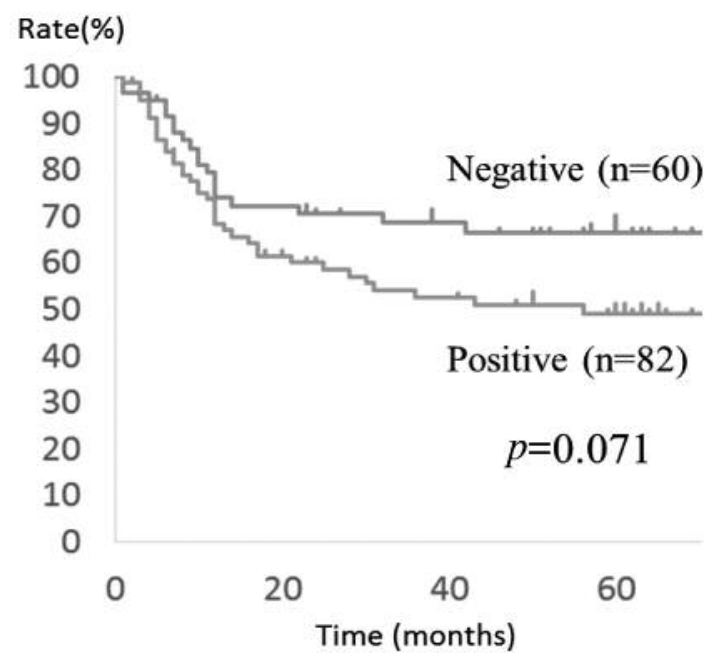

Figure 2. Kaplan-Meier analysis of five-year (A) overall and (B) disease-free survival stratified by MTA1 expression. Overall survival was significantly higher (69.9\%) in patients not expressing MTA1 than in patients expressing MTA1 $(50.7 \%, p=0.021)$, although disease-free survival was comparable at $66.5 \%$ and $49.0 \%$, respectively $(p=0.071)$.

updated) data. To our best knowledge, this is the first examination of the relationship among MTA1, LAT1, and ${ }^{18}$ F-FAMT uptake. We found that MTA1 expression was associated with less tissue differentiation and more aggressive invasion into surrounding tissues and vessels, and is thus likely to contribute to tumor malignancy, in line with previous studies (20). Indeed, MTA1 was originally identified from rat metastatic breast tumors, and abundant expression was subsequently observed in several types of cancer, highlighting its role in tumor metastasis (6), 
Table III. Expression of metastasis-associated gene 1 (MTA1) was predictive of overall and disease-free survival in univariate analysis. However, lymph node metastasis was the only statistically independent predictor of poor prognosis in multivariate analysis, with $p=0.034$ for overall survival and $p=0.020$ for disease-free survival.

\begin{tabular}{|c|c|c|c|c|c|c|c|c|c|c|c|c|c|}
\hline \multirow{3}{*}{$\begin{array}{l}\text { Variables } \\
\text { Parameter/Value/Number }\end{array}$} & & \multicolumn{6}{|c|}{ Overall survival } & \multicolumn{6}{|c|}{ Disease free survival } \\
\hline & & \multicolumn{3}{|c|}{ Univariate } & \multicolumn{3}{|c|}{ Multivariate } & \multicolumn{3}{|c|}{ Univariate } & \multicolumn{3}{|c|}{ Multivariate } \\
\hline & & HR & $95 \% \mathrm{CI}$ & $p$-Value & HR & $95 \% \mathrm{CI}$ & $p$-Value & $\mathrm{HR}$ & $95 \% \mathrm{CI}$ & $p$-Value & HR & $95 \% \mathrm{CI}$ & $p$-Value \\
\hline \multicolumn{14}{|l|}{ Age } \\
\hline$\leq 65$ & 81 & 0.88 & $0.53-1.46$ & 0.611 & & & & 0.60 & $0.35-1.05$ & 0.071 & & & \\
\hline$>65$ & 61 & & & & & & & & & & & & \\
\hline \multicolumn{14}{|l|}{ Gender } \\
\hline Female & 16 & 1.80 & $0.63-5.16$ & 0.275 & & & & 1.27 & $0.51-3.14$ & 0.610 & & & \\
\hline Male & 126 & & & & & & & & & & & & \\
\hline \multicolumn{14}{|l|}{ Histology } \\
\hline Well+Mod & 106 & 1.56 & $0.91-2.67$ & 0.108 & & & & 1.72 & $0.993-3.21$ & 0.053 & & & \\
\hline Poor & 36 & & & & & & & & & & & & \\
\hline \multicolumn{14}{|l|}{ Tumor Depth } \\
\hline pT1 & 63 & 2.51 & $1.45-4.35$ & 0.001 & 1.66 & $0.90-3.04$ & 0.102 & 3.20 & $1.77-5.77$ & $<0.001$ & 1.87 & $0.98-3.54$ & 0.056 \\
\hline pT2-4 & 79 & & & & & & & & & & & & \\
\hline \multicolumn{14}{|l|}{ Lymphnode metastasis } \\
\hline Absent & 59 & 2.57 & $1.46-4.53$ & 0.001 & 2.03 & $1.06-3.90$ & 0.034 & 3.42 & $1.84-6.37$ & $<0.001$ & 2.23 & $1.13-4.48$ & 0.020 \\
\hline Present & 83 & & & & & & & & & & & & \\
\hline \multicolumn{14}{|l|}{ Lymphatic permeation } \\
\hline Absent & 28 & 2.28 & $1.07-4.83$ & 0.032 & 0.79 & $0.27-2.34$ & 0.677 & 3.52 & $1.41-8.78$ & 0.007 & 1.25 & $0.37-4.21$ & 0.718 \\
\hline Present & 114 & & & & & & & & & & & & \\
\hline \multicolumn{14}{|l|}{ Venous invasion } \\
\hline Absent & 37 & 2.56 & $1.27-5.17$ & 0.009 & 1.56 & $0.64-3.81$ & 0.328 & 3.16 & $1.45-6.88$ & 0.004 & 1.49 & $0.60-3.74$ & 0.391 \\
\hline Present & 105 & & & & & & & & & & & & \\
\hline \multicolumn{14}{|l|}{ MTA1 expression } \\
\hline Negative & 60 & 1.82 & $1.06-3.12$ & 0.029 & 1.41 & $0.81-2.43$ & 0.223 & 1.65 & $0.95-2.86$ & 0.076 & 1.08 & $0.62-1.88$ & 0.783 \\
\hline Positive & 82 & & & & & & & & & & & & \\
\hline
\end{tabular}

HR, Hazard ratio; 95\% CI, 95\% confidence interval; Well, Well differentiated; Mod, moderately differentiated; Poor, poorly differentiated.

especially into lymph nodes (21). Although we did not observe a correlation between MTA1 and metastasis of esophageal cancer into lymph nodes, the latter was the only independent prognostic factor in multivariate analysis, and a significant relationship may indeed be found in a larger cohort.

MTA1 is abundantly expressed under hypoxic conditions to deacetylate hypoxia-inducible factor-1a (HIF-1a), which then induces expression of vascular endothelial growth factor (VEGF) to promote tumor angiogenesis $(3,22,23)$. Accordingly, we found that MTA1 expression correlated with CD34 expression, a marker of angiogenesis, suggesting that MTA1-induced HIF-1a/VEGF signaling is a key regulator of angiogenesis in ESCC.

Although ${ }^{18} \mathrm{~F}$-FDG and ${ }^{18} \mathrm{~F}$-FAMT PET are equally useful in treating esophageal cancer, there is a wide difference in uptake, mostly as a result of differences in data collection and processing. On one hand, ${ }^{18} \mathrm{~F}-\mathrm{FDG}$ uptake is measured as the sum of glucose transport and phosphoenzyme activity, and is relatively high. On the other hand, ${ }^{18} \mathrm{~F}$-FAMT uptake is due solely to amino acid transport, especially via LAT1 in malignant tumors, resulting in tumor-specific, but relatively low accumulation. Previously, we demonstrated that LAT1 expression is associated with 18F-FAMT accumulation, and we now demonstrate that MTA1 expression in tumor cells is correlated both with LAT1 expression $(p=0.013)$, and ${ }^{18} \mathrm{~F}$ FAMT accumulation $(p=0.036)$. Although we did not investigate the mechanism underlying this relationship, MTA1 is already known to elicit expression of tyrosine kinases such as VEGF via chromatin remodeling. In turn, the increased tyrosine kinase activity may stimulate demand for tyrosine, which in tumor cells is transported by LAT1 as noted $(15,24)$. Hence, although it is possible that LAT1 is epigenetically controlled via MTA1-induced chromatin remodeling, the data instead suggest that MTA1 alters amino acid metabolism in ESCC via tyrosine kinase, and thereby elicits LAT1 expression and ${ }^{18}$ F-FAMT accumulation. 
Furthermore, we found that MTA1 was abundantly expressed in cancer cells, but only weakly expressed in normal squamous epithelia $(21,25)$, in line with Miyashita et al. (26), who observed nuclear accumulation of MTA1 in all stages of squamous carcinogenesis, including at formation of proliferative squamous hyperplasia, dysplasia, and carcinoma. In light of this result, MTA1 and HDAC1 were proposed to be master coregulatory molecules involved in esophageal carcinogenesis.

MTA proteins physically interact with HDAC1 and HDAC2 (27-30) to epigenetically control gene expression by deacetylating histones and altering chromatin structure (4, 31, 32). Thus, MTA/HDAC complexes are intimately involved in normal transcriptional balance (33). Accordingly, HDAC-mediated epigenetic control is often dysregulated in numerous types of cancer (34), and HDAC inhibitors were reported to induce growth arrest, differentiation, and apoptosis in transformed cells, to interfere directly with the mitotic spindle checkpoint, and to disrupt the cell cycle at the $G_{2}$ phase, allowing cells to prematurely enter the $M$ phase (35). For example, Junfen et al. (34) demonstrated that the pan-HDAC inhibitor TSA inhibited cell proliferation, cell-cycle regulation, and apoptosis in esophageal squamous carcinoma cells, and suppressed PI3K/Akt and MAPK signaling (34). HDAC inhibitors were also reported to increase radio sensitivity, p21 expression, reactive oxygen species production, $\mathrm{G}_{2} / \mathrm{M}$ arrest, and apoptosis in the same cells, as well as to decrease the mitochondrial membrane potential (36). Thus, HDAC inhibitors are believed to be appropriate treatments for ESCC in combination with radiation therapy.

RNA interference against MTA1 was shown to downregulate integrin $\beta 1, \mathrm{p} 53, \mathrm{MMP} 9$, and pAkt; to upregulate E-cadherin, MDM2, and PTEN; and to reduce cell adhesion, wound healing, invasion, and migration in vivo (37-39) and in vitro (38). Hence, new strategies to inhibit MTA1, in combination with existing treatments, may provide new avenues to treat esophageal squamous cell cancer (21). Indeed, MTA1 silencing is an alternate strategy to specifically inhibit MTA1/HDAC complexes and avoid the side effects associated with general inhibition of HDACs (37).

We note that our data were collected exclusively from squamous cell carcinomas, which comprise the majority of cases in Japan and East Asia, although adenocarcinomas are prevalent in Europe. In addition, our cohort consisted of patients who underwent radical esophagectomy without preoperative therapy, although the number of such patients continues to decrease. Hence, our cohort consisted of the small sample size. Indeed, neoadjuvant therapy is now becoming standard therapy for Stage II and III esophageal cancer, while outcomes from definitive chemoradiation therapy have continued to improve. Moreover, although ${ }^{18} \mathrm{~F}$ -
FAMT PET was adopted in our institution in 2008, it has been discontinued due to the cost and limited availability of ${ }^{18} \mathrm{~F}$-FAMT. Hence, standardized uptake values for ${ }^{18} \mathrm{~F}$ FAMT were available for only 42 cases, and the small sample size may have biased results. In addition, ${ }^{18}$ F-FAMT is only weakly accumulated in tumors. Thus, fewer tissues are recognized as having taken up ${ }^{18}$ F-FAMT, resulting in lower mean standardized uptake values, and potentially biasing the comparison between tissues expressing or not expressing MTA1. Finally, our results indicate only a statistical relationship between MTA1 and LAT1 in tumor cells, and further investigation is required to definitively establish a functional relationship.

\section{Conclusion}

MTA1 alters amino acid metabolism and promotes angiogenesis in tumors via LAT1, CD34, and HIF1-a. Hence, MTA1 shows promise as a diagnostic and prognostic marker in esophageal cancer, and we anticipate that the gene will also prove to be a good therapeutic target.

\section{Acknowledgements}

The Authors appreciate Mr. Bolag Altan and Ms. Bao Halin for diligent technical assistance, and Ms. T Yano, Ms. Y Matsui, Ms. K Nakamura, and Ms. Yukie Saito for administrative assistance.

\section{References}

1 Ferlay J, Soerjomataram I, Dikshit R, Eser S, Mathers C, Rebelo M, Parkin DM, Forman D and Bray F: GLOBOCAN 2012 v1.0, Cancer Incidence and Mortality Worldwide: IARC CancerBase No. 11. [Internet] Lyon, France: International Agency for Research on Cancer; pp. cited 2015-06-25, 2013.

2 Toh Y, Pencil SD and Nicolson GL: A novel candidate metastasis-associated gene, mta1, differentially expressed in highly metastatic mammary adenocarcinoma cell lines. cDNA cloning, expression, and protein analyses. J Biol Chem 269: 22958-22963, 1994

3 Toh Y and Nicolson G: MTA1 of the MTA (metastasisassociated) gene family and its encoded proteins: molecular and regulatory functions and role in human cancer progression. Atlas Genet Cytogenet Oncol Haematol 15: 303-315, 2001.

4 Yoo Y-G, Kong G and Lee M-O: Metastasis-associated protein 1 enhances stability of hypoxia-inducible factor- 1 alpha protein by recruiting histone deacetylase 1 . EMBO J 25: 1231-1241, 2006.

5 Manavathi B and Kumar R: Metastasis tumor antigens, an emerging family of multifaceted master coregulators. J Biol Chem 282: 1529-1533, 2007.

6 Toh Y and Nicolson GL: Properties and clinical relevance of MTA1 protein in human cancer. Cancer Metastasis Rev 33: 891900, 2014.

7 Croteau E, Renaud JM, Richard MA, Ruddy TD, Bénard F and deKemp RA: PET metabolic biomarkers for cancer. Biomark Cancer 8: 61-69, 2016. 
8 Vansteenkiste JF, Stroobants SG, Dupont PJ, De Leyn PR, Verbeken EK, Deneffe GJ, Mortelmans LA and Demedts MG: Prognostic importance of the standardized uptake value on (18)F-fluoro-2-deoxy-glucose-positron emission tomography scan in non-small-cell lung cancer: an analysis of 125 cases. J Clin Oncol 17: 3201-3206, 1999.

9 Kato H, Nakajima M, Sohda M, Tanaka N, Inose T, Miyazaki T, Fukuchi M, Oriuchi N, Endo K and Kuwano H: The clinical application of (18)F-fluorodeoxyglucose positron emission tomography to predict survival in patients with operable esophageal cancer. Cancer 115: 3196-3203, 2009.

10 Inoue T, Tomiyoshi K, Higuichi T, Ahmed K, Sarwar M, Aoyagi $\mathrm{K}$, Amano S, Alyafei S, Zhang $\mathrm{H}$ and Endo K: Biodistribution studies on L-3-[fluorine-18]fluoro-alpha-methyl tyrosine: a potential tumor-detecting agent. J Nucl Med 39: 663-667, 1998.

11 Wiriyasermkul P, Nagamori S, Tominaga H, Oriuchi N, Kaira K, Nakao H, Kitashoji T, Ohgaki R, Tanaka H, Endou H, Endo K, Sakurai H and Kanai Y: Transport of 3-fluoro-L- $\alpha$-methyl-tyrosine by tumor-upregulated L-type amino acid transporter 1: a cause of the tumor uptake in PET. J Nucl Med 53: 1253-1261, 2012.

12 Kaira K, Ishizuka T, Yanagitani N, Sunaga N, Hisada T and Mori M: Value of FDG positron emission tomography in monitoring the effects of therapy in progressive pulmonary sarcoidosis. Clin Nucl Med 32: 114-116, 2007.

13 Sohda M, Kato H, Suzuki S, Tanaka N, Sano A, Sakai M, Inose T, Nakajima M, Miyazaki T, Fukuchi M, Oriuchi N, Endo K and Kuwano H: ${ }^{18}$ F-FAMT-PET is useful for the diagnosis of lymph node metastasis in operable esophageal squamous cell carcinoma. Ann Surg Oncol 17: 3181-3186, 2010.

14 Honjo H, Kaira K, Miyazaki T, Yokobori T, Kanai Y, Nagamori $\mathrm{S}$, Oyama T, Asao T and Kuwano H: Clinicopathological significance of LAT1 and ASCT2 in patients with surgically resected esophageal squamous cell carcinoma. J Surg Oncol 113: 381-389, 2016.

15 Suzuki S, Kaira K, Ohshima Y, Ishioka NS, Sohda M, Yokobori T, Miyazaki T, Oriuchi N, Tominaga H, Kanai Y, Tsukamoto N, Asao T, Tsushima Y, Higuchi T, Oyama T and Kuwano H: Biological significance of fluorine-18- $\alpha$-methyltyrosine (FAMT) uptake on PET in patients with oesophageal cancer. Br J Cancer 110: 1985-1991, 2014.

16 Hamilton SR and Aaltonen LA: WHO classification of tumours of the digestive system. Lyon, France: International Agency for Research on Cancer, 2010.

17 Sobin LH, Gospodarowicz MK and Wittekind Ch: TNM classification of malignant tumors, Seventh edition. Oxford, UK: Wiley-Blackwell, 2009.

18 Kaira K, Oriuchi N, Imai H, Shimizu K, Yanagitani N, Sunaga N, Hisada T, Tanaka S, Ishizuka T, Kanai Y, Endou H, Nakajima $\mathrm{T}$ and Mori M: Prognostic significance of L-type amino acid transporter 1 expression in resectable stage I-III nonsmall cell lung cancer. Br J Cancer 98: 742-748, 2008.

19 Sakata T, Ferdous G, Tsuruta T, Satoh T, Baba S, Muto T, Ueno A, Kanai Y, Endou $\mathrm{H}$ and Okayasu I: L-type amino-acid transporter 1 as a novel biomarker for high-grade malignancy in prostate cancer. Pathol Int 59: 7-18, 2009.

20 Li SH, Tian H, Yue WM, Li L, Gao C, Li WJ, Hu WS and Hao B: Metastasis-associated protein 1 nuclear expression is closely associated with tumor progression and angiogenesis in patients with esophageal squamous cell cancer. World J Surg 36: 623$631,2012$.
21 Toh Y, Ohga T, Endo K, Adachi E, Kusumoto H, Haraguchi M, Okamura T and Nicolson GL: Expression of the metastasisassociated MTA1 protein and its relationship to deacetylation of the histone $\mathrm{H} 4$ in esophageal squamous cell carcinomas. Int J Cancer 20: 362-367, 2004.

22 Nagaraj SR, Shilpa P, Rachaiah K and Salimath BP: Crosstalk between VEGF and MTA1 signaling pathways contribute to aggressiveness of breast carcinoma. Mol Carcinog 54: 333-350, 2015.

23 Moon HE, Cheon H, Chun KH, Lee SK, Kim YS, Jung BK, Park JA, Kim SH, Jeong JW and Lee M: Metastasis-associated protein 1 enhances angiogenesis by stabilization of HIF-1alpha. Oncol Rep 16: 929-935, 2006.

24 Kaira K, Takahashi T, Murakami H, Shukuya T, Kenmotsu H, Naito T, Oriuchi N, Kanai Y, Endo M, Kondo H, Nakajima T and Yamamoto N: Relationship between LAT1 expression and response to platinum-based chemotherapy in non-small cell lung cancer patients with postoperative recurrence. Anticancer Res 31: 3775-3782, 2011.

25 Jang KS, Paik SS, Chung H, Oh YH and Kong G: MTA1 overexpression correlates significantly with tumor grade and angiogenesis in human breast cancers. Cancer Sci 97: 374-379, 2006.

26 Miyashita T, Tajima H, Munemoto M, Shah FA, Harmon JW, Watanabe T, Shoji M, Okamoto K, Nakanuma S, Sakai S, Kinoshita J, Makino I, Nakamura K, Hayashi H, Oyama K, Inokuchi M, Nakagawara H, Takamura H, Ninomiya I, Kitagawa H, Fushida S, Mukaisho K, Fujimura T and Ohta T: Impact of histone deacetylase 1 and metastasis-associated gene 1 expression in esophageal carcinogenesis. Oncol Lett 8: 758-764, 2014.

27 Toh Y, Kuninaka S, Endo K, Oshiro T, Ikeda Y, Nakashima H, Baba H, Kohnoe S, Okamura T, Nicolson GL and Sugimachi K: Molecular analysis of a candidate metastasis-associated gene, MTA1: possible interaction with histone deacetylase 1. J Exp Clin Cancer Res 19: 105-111, 2000.

28 Denlinger CE, Keller MD, Mayo MW, Broad RM and Jones DR: Combined proteasome and histone deacetylase inhibition in nonsmall cell lung cancer. J Thorac Cardiovasc Surg 127: 10781086, 2004

29 Warrell RP Jr., He LZ, Richon V, Calleja E and Pandolfi PP: Therapeutic targeting of transcription in acute promyelocytic leukemia by use of an inhibitor of histone deacetylase. J Natl Cancer Inst 90: 1621-1625, 1998.

30 Phillips T, Collins T and Davies J: American Association for Cancer Research-96th Annual Meeting. Targeting the cell cycle and HDAC inhibitors. IDrugs 8: 450-453, 2005.

31 Kumar R, Wang RA and Bagheri-Yarmand R: Emerging roles of MTA family members in human cancers. Semin Oncol 30: 3037, 2003.

32 Manavathi B, Peng S, Rayala SK, Talukder AH, Wang MH, Wang RA, Balasenthil S, Agarwal N, Frishman LJ and Kumar $\mathrm{R}$ : Repression of Six 3 by a corepressor regulates rhodopsin expression. Proc Natl Acad Sci USA 104: 13128-13133, 2007.

33 Toh Y and Nicolson GL: The role of the MTA family and their encoded proteins in human cancers: molecular functions and clinical implications. Clin Exp Metastasis 26: 215-227, 2009.

34 Ma J, Guo X, Zhang S, Liu H, Lu J, Dong Z, Liu K and Ming L: Trichostatin A, a histone deacetylase inhibitor, suppresses proliferation and promotes apoptosis of esophageal squamous cell lines. Mol Med Rep 11: 4525-4531, 2015. 
35 Taddei A, Roche D, Bickmore WA and Almouzni G: The effects of histone deacetylase inhibitors on heterochromatin: implications for anticancer therapy? EMBO Rep 6: 520-524, 2005.

36 Dong Q, Sharma S, Liu H, Chen L, Gu B, Sun X and Wang G: HDAC inhibitors reverse acquired radio resistance of KYSE150R esophageal carcinoma cells by modulating Bmi-1 expression. Toxicol Lett 224: 121-129, 2014.

37 Mazumdar A, Wang RA, Mishra SK, Adam L, Bagheri-Yarmand R, Mandal M, Vadlamudi RK and Kumar R: Transcriptional repression of oestrogen receptor by metastasis-associated protein 1 corepressor. Nat Cell Biol 3: 30-37, 2001.
38 Qian H, Lu N, Xue L, Liang X, Zhang X, Fu M, Xie Y, Zhan Q, Liu $\mathrm{Z}$ and Lin C: Reduced MTA1 expression by RNAi inhibits in vitro invasion and migration of esophageal squamous cell carcinoma cell line. Clin Exp Metastasis 22: 653-662, 2005.

39 Rao YM, Ji M, Chen CH and Shi HR: Effect of siRNA targeting MTA1 on metastasis malignant phenotype of ovarian cancer A2780 cells. J Huazhong Univ Sci Technolog Med Sci 33: 266$271,2013$.

Received April 28, 2017

Revised June 6, 2017

Accepted June 19, 2017 